\title{
Marchiafava-Bignami disease in an AIDS patient
}

\author{
Doença de Marchiafava-Bignami em um paciente com AIDS \\ Marcus Vinicius Pinto ${ }^{1}$, André Bon², Valéria Carvalho Costa², Fábio Noro ${ }^{3}$, Marco Antônio Lima ${ }^{1}$
}

A 40 year-old alcoholic man with AIDS developed acute encephalopathy and fever. Brain MRI showed a diffuse corpus callosum(CC) and periventricular white matter demyelinating lesions (Figure), suggestive of Marchiafava-Bignami disease (MBD). CD4 T lymphocyte count was $2 / \mathrm{mm}^{3}$, HIV viral load was $750000 / \mathrm{mm}^{3}$. CSF analysis was normal. Parenteral B vitamins were started with rapid improvement.
MBD is metabolic disease characterized by demyelination of the CC, which occurs in severe alcoholism and malnourished states ${ }^{1}$, rarely associated with AIDS. The main differential diagnosis of $\mathrm{CC}$ lesions are multiple sclerosis, lymphoma, viral encephalitis and stroke ${ }^{2}$.

MBD must always be considered in alcoholics with encephalopathy despite of their immune status.
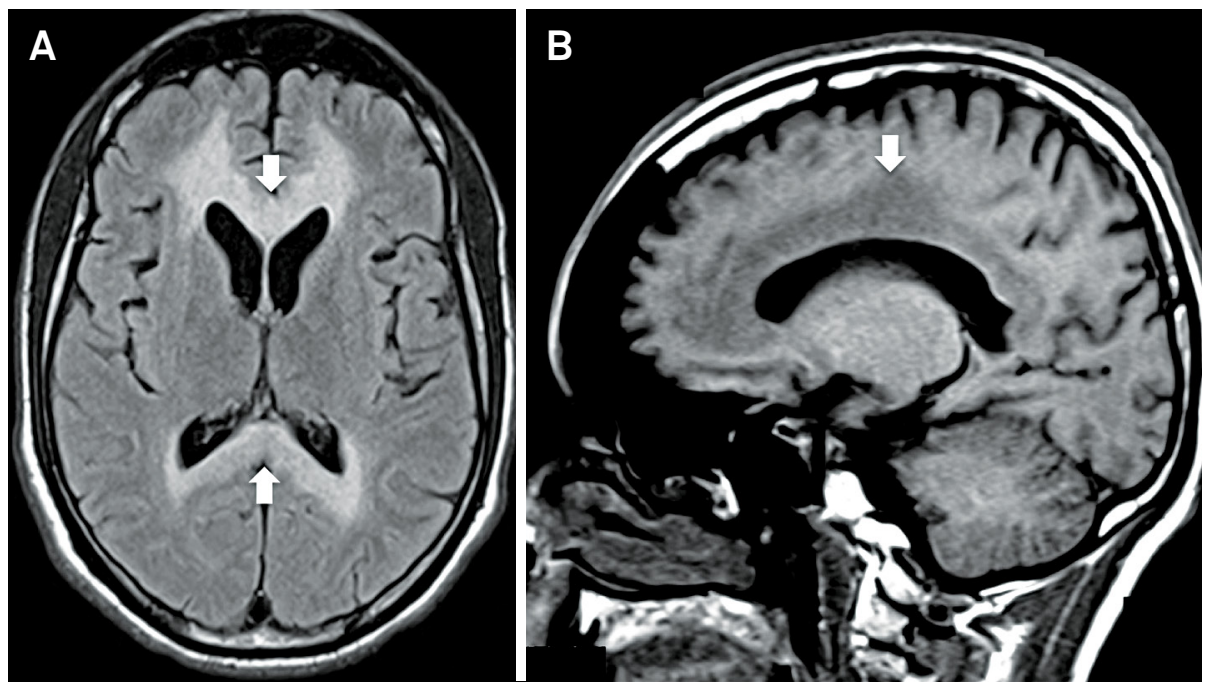

Figure. (A) Axial FLAIR image shows high signal intensity in anterior and posterior portions of the Corpus Callosum (white arrows) and periventricular white matter. (B) Sagital T1-weighted image shows low signal intensity along the entire lenght of the Corpus Callosum (white arrow).

1. Hillbom M, Saloheimo P, Fujioka S, Wszolek ZK, Juvela S, Leone MA. Diagnosis and management of Marchiafava-Bignami disease: a review of CT/MRI confirmed cases. J Neurol Neurosurg Psychiatry. 2014;85(2):168-73. doi:10.1136/jnnp-2013-305979
2. Renard D, Castelnovo G, Campello C, Bouly S, Le Floch A, Trouvenot $E$ et al. An MRI review of acquired corpus callosum lesions. J Neurol Neurosurg Psychiatry. 2014;85(9):1041-8. doi:10.1136/jnnp-2013-307072

\footnotetext{
${ }^{1}$ Universidade Federal do Rio de Janeiro, Hospital Universitário Clementino Fraga Filho, Departamento de Neurologia, Rio de Janeiro RJ, Brazil; ${ }^{2}$ Universidade Federal do Rio de Janeiro, Hospital Universitário Clementino Fraga Filho, Departamento de Doenças Infecciosas e Parasitárias, Rio de Janeiro RJ, Brazil;

${ }^{3}$ Universidade Federal do Rio de Janeiro, Hospital Universitário Clementino Fraga Filho, Departamento de Radiologia, Rio de Janeiro RJ, Brazil.

Correspondence: Marcus Vinicius Pinto; Departamento de Neurologia, Hospital Universitário Clementino Fraga Filho; Avenida Brigadeiro Trompowiski, s/n; 21941-590 Rio de Janeiro RJ, Brasil; E-mail: mvrpinto@gmail.com 